\title{
Genetic algorithms optimization of hedging rules for operation of the multi-purpose Ubonratana Reservoir in Thailand
}

\author{
CHUTHAMAT CHIAMSATHIT, A. J. ADELOYE \& B. SOUNDHARAJAN \\ School of the Built Environment, Heriot-Watt University, Riccarton, Edinburgh EH14 4AS, UK \\ a.j.adeloye@hw.ac.uk
}

\begin{abstract}
This study has developed optimal hedging policies for the multi-purpose Ubonratana Reservoir in northeastern Thailand based on its existing rule curves. The hedging policy was applied whenever the reservoir storage falls below a critical level for each month of the year. The decision variables, i.e. the set of monthly storages defining the critical rule curve that triggers rationing and the rationing ratio, were optimized by genetic algorithm (GA). Both single stage (i.e. with one critical rule curve and one rationing ratio) and two-stage (with two critical rule curves and ratios) of the hedging policy were considered in the optimization. To test the effect of the optimized hedging policies on reservoir performance, simulations were carried out, forced alternatively with the existing rule curves (i.e. without hedging) and the two optimized hedging policies. Performance was summarized in terms of reliability (time- and volume-based) and vulnerability. The results showed that the vulnerability was significantly reduced by using the optimized hedging rules. However, the number of water shortages increased with the optimized rules, causing the time-based reliability to worsen significantly. This should not be of concern since, although the number of shortages increased, the associated shortage quantities on most of these additional occasions were small, leaving the volumetric reliability largely unchanged.
\end{abstract}

Key words reservoir operation; rule curves; hedging policy; Ubonratana, Thailand; sustainability

\section{INTRODUCTION}

Drought is one of the most serious water resources problems in northeastern Thailand due to the uncertainty in monsoon rainfall patterns. Water scarcity due to drought affects the agricultural sector, which is the major economic activity in the region, thus hampering the rural economy and people's livelihoods. Increasing water demands due to increases in population and acreage cultivated for food production, in combination with the temporal and spatial variability in river flow and rainfall, make irrigation inevitable. Indeed, agricultural production in northeastern Thailand relies heavily on irrigation and the Ubonratana Reservoir is the main infrastructure regulating river flows for irrigation, as well other consumptive uses including domestic and industrial water supply, hydropower generation and low flows augmentation. In addition to its regulating functions, Ubonratana is also relied on for flood protection and operating the reservoir for these conflicting objectives remains a daunting challenge.

The operation of Ubonratana has been guided for a long time using rule curves. However, such an approach saves no water for impending droughts and the consequence is that the resulting shortage during such droughts can be very large. This problem can be tempered by water rationing during normal operational periods so that rather than supply their full demands, the supply is curtailed and the saved water can be used to limit the amount and impact of any water shortages during droughts (Tu et al. 2008, Eum et al. 2011).

The main challenge in hedging, however, is establishing the timing and amount of the rationing since inability to establish these correctly may be counterproductive. For example, too little rationing may not solve the crippling water shortage problem during future droughts, while too much rationing may turn out to be unnecessarily punitive. The way the hedging problem has been traditionally approached is to use optimisation techniques to develop hedging rules by modifying the standard operating policy (SOP) during droughts and impending droughts (Tu et al. 2008). However, the SOP is not the ideal policy for reservoir operation in that, by default, it produces large, single period shortage or vulnerability. Additionally, previous efforts that used the SOP as the basis of hedging policy development have attempted to hedge in regions of the SOP when water is already in short supply. For hedging to be useful, the water saving must be done during periods of normal reservoir operation; not when the water is already in short supply. Thus, this study has not used the SOP as the basis for the optimised hedging policy; rather, the existing rule curves for the Ubonratana formed the basis of the optimisation. 
Consequently, this work has developed an optimised hedging policy for the Ubonratana based on the existing rule curves for the multipurpose reservoir. The optimisation used Genetic Algorithms (GA) whose fitness function was the sum of squares of the water deficits.

\section{METHODOLOGY}

\section{Rule curves and hedging for operation of single reservoir system}

Figure 1(b) and (c) conceptualises single-stage and two-stage hedging, as developed in this study from the no-hedging policy in Fig. 1(a). The upper rule curve (URC) defines the maximum level for flood control purposes, the lower rule curve (LRC) defines the limit for conservation purposes, and the critical rule curve (CR) defines the trigger for rationing at the associated ratio. The distinguishing feature between the single-stage and the two-stage is that the former has one critical rule curve (and one associated rationing ratio), while the latter has two such critical curves and ratios. Thus, in comparison with the no-hedging rule curve illustrated in Fig. 1(a), normal operation in which the supply of full demand is attempted only occurs when the reservoir storage is outside the critical storage zones. Consequently, for the single-stage hedging policy (Fig. 1(b)), whenever the starting reservoir storage is below the critical rule curve, the water delivery is rationed by delivering only a fraction of the full demand, i.e. $D_{t}^{\prime}=\alpha D_{t}$, where $D_{t}^{\prime}$ is the supply, $D_{t}$ is the demand and $\alpha(0 \leq \alpha \leq 1)$ is the rationing ratio. For the two-stage hedging policy (Fig. 1(c)), the rationing is done in two levels of critical rule curves and two rationing factors to supply $\alpha_{1} D_{t}$ and $\alpha_{2} D_{t}$, respectively, where $0 \leq \alpha_{2} \leq$ $\alpha_{1} \leq 1$. The determination of the critical rule curves and the associated hedging factors $\alpha, \alpha_{1}$ and $\alpha_{2}$ is achieved by GA optimisation. Although the hedging factors could also be time-dependent, this analysis has been restricted to constant factors for simplicity sake.
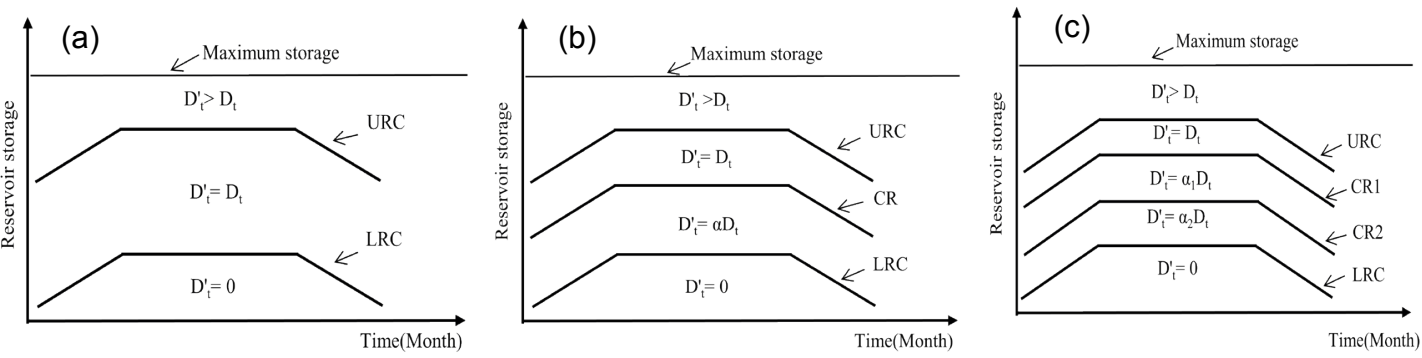

Fig. 1 Schematic illustration of hedging rules showing (a) no-hedging (b) single-stage hedging and (c) two-stage hedging.

\section{Formulation of optimisation of hedging rules}

The objective function and constraints are as follows.

The objective function is to minimise the sum of squares of the period shortages, i.e.:

$$
\text { Minimise } \sum\left(D_{t}-D_{t}^{\prime}\right)^{2} \quad \forall D_{t}^{\prime} \leq D_{t}
$$

The constraints are as follows:

Single-stage hedging

$W A_{t}=S_{t}+Q_{t}$

if $W A_{t} \geq U R C_{t}, \quad D_{t}^{\prime}=S_{t}+Q_{t}-E_{t}-U R C_{t} \& Y_{t}=D_{t}^{\prime}-D_{t}$

if $U R C_{t} \geq W A_{t}>C R_{t}, \quad D_{t}^{\prime}=D_{t} \& Y_{t}=0$

if $C R_{t} \geq W A_{t}>L R C_{t}, \quad D_{t}^{\prime}=\alpha D_{t}$

if $W A_{t} \leq L R C_{t}, \quad D_{t}^{\prime}=0$

$S_{t+1}=S_{t}+Q_{t}-D_{t}^{\prime}-E_{t}$

$1 \geq \alpha \geq 0$

$U R C_{t} \geq C R_{t} \geq L R C_{t}$
Two-stage hedging

$W A_{t}=S_{t}+Q_{t}$

if $W A_{t} \geq U R C_{t}, \quad D_{t}^{\prime}=S_{t}+Q_{t}-E_{t}-U R C_{t} \& Y_{t}=D^{\prime}{ }_{t}-D_{t}$

if $U R C_{t} \geq W A_{t}>C R 1_{t}, \quad D_{t}^{\prime}=D_{t}$

if $C R 1_{t} \geq W A_{t}>C R 2_{t}, \quad D_{t}^{\prime}=\alpha_{1} D_{t}$

if $C R 2_{t} \geq W A_{t}>L R C_{t}, \quad D_{t}^{\prime}=\alpha_{2} D_{t}$

if $W A_{t} \leq L R C_{t}, D_{t}^{\prime}=0$

$S_{t+1}=S_{t}+Q_{t}-D_{t}^{\prime}-E_{t}$

$1 \geq \alpha_{1} \geq \alpha_{2} \geq 0$

$U R C_{t} \geq C R 1_{t} \geq C R 2_{t} \geq L R C_{t}$ 
where $D_{t}$ is the water demand during period $t ; D_{t}^{\prime}$ is the water delivery during period $t ; S_{t}$ is storage at beginning of time $t ; S_{t+l}$ is the storage at the end of time $t ; Q_{t}$ is the inflow to the reservoir during $t ; E_{t}$ is the evaporation loss during time $t ; Y_{t}$ is the excess water released during period $t ; W A_{t}$ is the water available at time $t$.

\section{Genetic algorithm}

GA optimisation was selected for the study because the technique has been widely applied for reservoir operational studies with great success; excellent reviews of some of the recent studies are provided by Hossain and El-shafie (2013) and Rani and Moreira (2010). In a GA, the solution set is represented by a population of chromosomes, with each chromosome being made up of the individual decision variables of the problem. These decision variables are also referred to as genes. Chromosomes are processed and combined according to their fitness, in order to generate new chromosomes that have the best features of two parents. Three fundamental operations are involved in manipulating the chromosomes and moving to a new generation: selection, crossover, and mutation (Michalewicz 1992). The current optimisation used a population size of 700 and the initial sampling of the real-coded decision variables was based on the uniform density function. After estimating the fitness values for each individual (chromosome), next generation individuals were selected based on fitness ranking (Wardlaw and Sheriff 1999) and the Roulette selection method. The selected individuals reproduce children for the next generation, which is based on the crossover (crossover fraction $=0.8$ ) and mutation (mutation rate $=0.01$ ). Two elite children were assumed. The genetic operations were repeated for 500 generations.

The decision variables for the hedging optimisation are the critical reservoir storage (CR) levels for each month of the year and the rationing factor $(\alpha)$. Thus, the numbers of decision variables are 13 and 26 for single-stage and two-stage hedging scenarios, respectively. In the single-stage hedging, decision variables 1 to 12 represent the monthly CR values and decision variable 13 represents the rationing ratio $(\alpha)$. Similarly, in the two-stage hedging, decision variables 1 to 12 and 13 to 24 represent CR1 and CR2, respectively; decision variables 25 and 26 represent $\alpha_{1}$ and $\alpha_{2}$, respectively.

\section{Evaluated Performance Indices}

To test the effectiveness of the hedging policies, reservoir simulations were carried out and relevant performance measures - reliability (time- and volume-based) and vulnerability (McMahon et al. 2006) - were evaluated as outlined below.

- Time-based Reliability $\left(R_{t}\right)$ is the proportion of the total time period under consideration during which a reservoir can meet the full demand without any shortages:

$$
R_{t}=N_{s} / N
$$

where $N_{s}$ is the total number of intervals out of $N$ that the demand was met.

- Volume-based Reliability $\left(R_{v}\right)$ is the total quantity of water actually supplied divided by the total quantity of water demanded during the entire operational period:

$$
R_{v}=\sum_{t=1}^{N} D_{t}^{\prime} / \sum_{t=1}^{N} D_{t}, \forall \mathrm{D}_{\mathrm{t}}^{\prime} \leq \mathrm{D}_{\mathrm{t}}
$$

- Vulnerability is the average period shortfall as a ratio of the average period demand (Sandoval-Solis et al. 2011):

$$
\eta=\frac{\sum_{t=1}^{f_{d}}\left[\left(D_{t}-D_{t}^{\prime}\right) / D_{t}\right]}{f_{d}} ; t \in f_{d}
$$

where $\eta$ is vulnerability (dimensionless), $f_{d}$ is the total duration of the failures, i.e. $f_{d}=N-N_{s}$ and all other terms are as defined previously. 


\section{Study area and input data}

The Ubonratana Reservoir is the largest $\left(\right.$ capacity $=2431 \mathrm{Mm}^{3}$ ) reservoir in the upper Chi River basin in northeastern Thailand. The dam is located on the Pong River at Phong Neap, Ubonratana district in Khon Kaen province, between latitudes $16^{\circ}$ and $17^{\circ} 30^{\prime} \mathrm{N}$ and longitudes $101^{\circ} 15^{\prime \prime}$ and $102^{\circ} 45^{\prime \prime} \mathrm{E}$. The single, multi-purpose reservoir has been operated for a long time using rule curves developed by the Electricity Generating Authority of Thailand (EGAT), the dam operators. The dam provides water for consumptive uses (domestic, industrial, irrigation), Pong River instream flow augmentation, hydropower generation (installed capacity $=25.2 \mathrm{MW}$ ) and flood control (EGAT, 2002). All the water deliveries first pass through the turbines for power generation before being allocated to the other uses. This study used the reservoir inflow data of 384 months (19802012). Gross water requirements (domestic, industrial, irrigation, instream flow) for the 384 months was $30140 \mathrm{Mm}^{3}$, i.e. a monthly average of $78.49 \mathrm{Mm}^{3}$.

\section{RESULTS AND DISCUSSION}

The optimised values for the decision variables are shown in Table 1. For convenience, the nohedging policy is denoted by $\mathrm{H} 0$, while the single-stage and two-stage integrated hedging rules curves are denoted by $\mathrm{H} 1$ and $\mathrm{H} 2$, respectively. Figure 2(a) and (b) are the graphical illustration of the optimised hedging policies. In general the optimised critical rule curves fulfil the specified constraints, since for example both critical rule curves are bounded by the upper and lower rule curves, and the second stage critical rule curve is everywhere below the first stage critical curve for the two-stage hedging policy. The optimised rationing ratios obtained and shown in Table 1 are also well behaved, with both of the met water demands for the two-stage rationing being greater than the single-stage rationing. While only $82 \%$ of the full demand is met during rationing for the single stage, the first and second stages of the rationing in the 2-stage policy met 92 and $84 \%$, respectively of the full demands. Also for the 2-stage policy, the second stage rationing is more restricted (i.e. less water is supplied) than the first stage rationing, as expected.

Table 1 Ordinates $\left(\mathrm{Mm}^{3}\right)$ of tested rule curves and operating policies

\begin{tabular}{lllllllllllllll}
\hline Policy & $\begin{array}{l}\text { Ration } \\
\text { ratio }\end{array}$ & $\begin{array}{l}\text { Rule } \\
\text { Curve }\end{array}$ & Apr & May & Jun & Jul & Aug & Sep & Oct & Nov & Dec & Jan & Feb & Mar \\
\hline H0 & - & URC & 1371 & 1127 & 946 & 797 & 906 & 1441 & 1902 & 1902 & 1902 & 1820 & 1740 & 1557 \\
& & LRC & 843 & 748 & 661 & 582 & 621 & 661 & 869 & 869 & 869 & 797 & 772 & 748 \\
H1 & 0.82 & CR & 1087 & 1014 & 946 & 615 & 865 & 975 & 1485 & 1486 & 1431 & 1332 & 1195 & 1132 \\
H2 & 0.92 & CR1 & 1071 & 906 & 775 & 748 & 832 & 1045 & 1765 & 1825 & 1721 & 1454 & 1643 & 1305 \\
& 0.84 & CR2 & 960 & 820 & 754 & 586 & 806 & 984 & 1151 & 1746 & 1509 & 977 & 1361 & 1296 \\
\hline
\end{tabular}

The results of the performance simulations for the different rule curves are summarised in Table 2. In terms of the total amount of water released over the 384 months of the simulation, H0 was marginally better than the other two; however, this may have masked incidences of large single period shortages with H0. The vulnerability $(\eta)$ is a measure of the impact of large single period shortages and as shown in Table 2, the vulnerability for $\mathrm{H} 0$ is almost 2.4 times as high as that for $\mathrm{H} 1$. This situation highlights the benefit of water saving during normal reservoir operation because it can bring about a significant reduction in the impacts (or vulnerability) of water shortage.

A reduction in the number and amount of large single-period shortages often comes at the expense of larger number of periods of moderate and small water shortages, and this is no exception in the current study. For example as seen in Table 2, while the number of occasions in which demand was unmet was only 31 for $\mathrm{H} 0$, this has grown to 82 and 99 for $\mathrm{H} 1$ and $\mathrm{H} 2$, respectively. This has in turn affected the systems time-based reliability, $R_{t}$, which deteriorated from about $92 \%$ for $\mathrm{H} 0$ to $79 \%$ and $74 \%$ for $\mathrm{H} 1$ and $\mathrm{H} 2$, respectively. However, as noted by Adeloye (2012), this should not be a source of concern since in terms of water availability as characterised by the volumetric reliability, $R_{v}$, the systems performance is still largely acceptable. 
Table 2 Summary of evaluated reservoir performance indices for the tested hedging policies.

\begin{tabular}{llllllll}
\hline Policy & $\begin{array}{l}\text { Total period } \\
\text { demand } \\
\left(\mathrm{Mm}^{3}\right)\end{array}$ & $\begin{array}{l}\text { Total period } \\
\text { release } \\
\left(\mathrm{Mm}^{3}\right)\end{array}$ & $\begin{array}{l}\text { Total period } \\
\text { deficit } \\
\left(\mathrm{Mm}^{3}\right)\end{array}$ & $\begin{array}{l}\mathrm{R}_{d} \\
\mathrm{R}, \\
(\%)\end{array}$ & $\begin{array}{l}\mathrm{R}_{\mathrm{v}} \\
(\%)\end{array}$ & $\eta$ \\
\hline H0 & 30140 & 28640 & 1500 & 31 & 91.93 & 95.02 & 0.70 \\
H1 & 30140 & 28412 & 1728 & 82 & 78.65 & 94.27 & 0.29 \\
H2 & 30140 & 28333 & 1807 & 99 & 74.22 & 94.00 & 0.26 \\
\hline
\end{tabular}
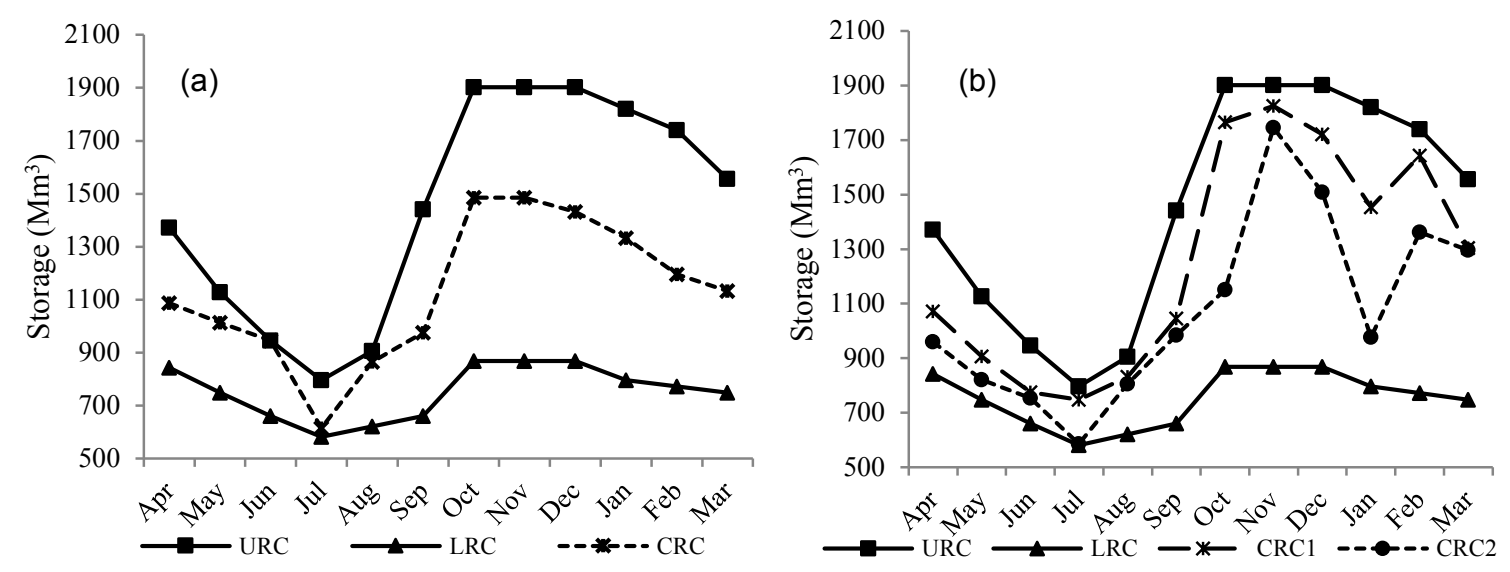

Fig. 2 Optimised hedging rules at Ubonratana for: (a) single-stage (H1) and (b) two-stage (H2).

\section{CONCLUSION}

This study has developed optimised hedging policies based on the existing rule curves at Ubonratana Reservoir in northeastern Thailand. The significant feature of the reported work is that single-stage and two-stage hedging policies were developed using GA to obtain the decision variables. Subsequent reservoir simulations to test the effectiveness of the hedging rules show that significant reduction in the number of large single-period water shortages can be achieved by rationing, resulting in manageable vulnerability for the Ubonratana. Reducing the number of large shortages caused the total number of failure periods to rise, leading to significant deterioration in the evaluated time-based reliability at Ubonratana. However, since the amount of water shortages for most of these additional shortage periods was low to moderate, the overall volumetric reliability of the reservoir was practically unaffected. This is re-assuring since what should matter most in reservoir operation is not the number of failure occasions but the deficit sustained during such failures. In terms of the vulnerability, the two-stage hedging outperformed both the singlestage and no-hedging policies. This might be an indication that further refinements of the hedging policy to include for example three stages or four stages might be warranted and this aspect is being taken up as the next stage of this study.

\section{REFERENCES}

Adeloye, A. J. (2012) Hydrological sizing of water supply reservoir. In: Encyclopedia of Lakes and Reservoirs (ed. by L. Bengtsson, R. W. Herschy and R. W. Fairbridge), Springer, Dordrecht, 346-355.

EGAT (2002) Improved Rule Curve. In: Procedure of the Ubonratana Reservoir operation: Electricity Generating Authority of Thailand (EGAT) in the Ubonratana dam

Eum, H., Kim, Y. and Palmer, R. (2011) Optimal Drought Management Using Sampling Stochastic Dynamic Programming with a Hedging Rule, Journal of Water Resources Planning and Management 137(1), 113-122.

Hossain, M.S. and El-shafie, A. (2013) Intelligent systems in optimizing reservoir operation policy: a review. Water Resources Management 27, 3387-3407.

McMahon, T. A., Adeloye, A. J. and Zhou, S. L. (2006) Understanding performance measures of reservoirs, Journal of Hydrology 324, 359-382.

Michalewicz, Z. (1992) Genetic Algorithms + Data Structures = Evolution Programs. Springer, New York.

Rani, D. and Moreira, M. M. (2010) Simulation-Optimisation modeling: a survey and potential application in reservoir systems operations. Water Resources Management 24, 1107-1138. 
Sandoval-Soils, S, Mckinney, D. C. and Loucks, D. P. (2011) Sustainability index for water resources planning and management. Water Resources Planning and Management, ASCE 137(5), 381-389.

$\mathrm{Tu}$, M., et al. (2008) Optimization of hedging rules for reservoir operations. Journal Water Resources Planning and Management 134(1), 3-13.

Wardlaw, R. and Sharif, M. (1999) Evaluation of genetic algorithms for optimal reservoir operation. Journal of Water Resources Planning and Management (ASCE) 125, 25-33. 